\title{
LENGUAS DOMINADAS IDEOLOGÍA Y VIOLENCIA LINGÜÍSTICA EN EL MAPUDUNGUN
}

\author{
DOMINATED LANGUAGES \\ IDEOLOGY AND LINGUISTIC VIOLENCE IN MAPUDUNGUN
}

\section{CHICHAM DEPETKIMU. ANEGTAIMSA NUIGTU WAITKANIAMU CHICHAMNUM MAPUDUNGUN ${ }^{(1)}$}

\author{
Javier Álvarez Vandeputte ${ }^{(2)}$ \\ Cristián Lagos Fernández ${ }^{(3)}$ \\ Universidad de Chile
}

\begin{abstract}
Resumen: Este artículo propone elementos para el desarrollo de una sociología de las lenguas minoritarias. Plantea la necesidad de un diálogo entre ciencias sociales y lingüística para la caracterización y la situación de dominación lingüística. Para ello propone la complementariedad entre las perspectivas de las ideologías y violencias lingüísticas. En términos metodológicos, el artículo sistematiza la literatura sobre ideologías lingüísticas desarrollada por Krotskity y Silverstein y los trabajos de Pierre Bourdieu sobre violencia y habitus lingüístico. Ambas conceptualizaciones son revisadas a la luz de evidencia primaria y secundaria sobre la situación de la lengua de los mapuches, el mapudungun, en Chile. El artículo concluye con una discusión sobre las posibilidades sociológicas de una liberación lingüística de los pueblos indígenas y mapuche.
\end{abstract}

Palabras clave: Mapudungun, ideologías lingüísticas, habitus lingüístico, violencia lingüística descolonización lingüística.

\footnotetext{
(1) Traduccion: Clelia Jima Chamiquit. Lengua indígena: Awajun

(2) Sociólogo de la Pontificia Universidad Católica. Magister en Ciencias Sociales por la Universidad de Chile. Investigador del Centro de Saberes docentes de la Universidad de Chile. Especialista en estudios de etnicidad, interculturalidad, modelos de evaluación. E-mail: pablo.alvarez.v@uchile.cl

(3) Antropólogo Social por la Universidad de Chile, Magister en Lingüística, Doctor en Filología Hispánica. Académico en las áreas de Lingüística estructural y etnolingüística del Departamento de Lingüística de la Universidad de Chile. E-mail: kinelagos@uchile.cl
} 
Abstract: This article proposes elements for the development of a sociology of minority languages. It raises the need for a dialogue between the social sciences and linguistics for the characterization and the situation of linguistic dominance. For this, he proposes the complementarity between the perspectives of ideologies and linguistic violence. In methodological terms, the article systematizes the literature on linguistic ideologies developed by Krotskity and Silverstein and the works of Pierre Bourdieu on violence and linguistic habitus. Both conceptualizations are reviewed in the light of primary and secondary evidence on the situation of the Mapuche language, Mapudungun, in Chile. The article concludes with a discussion on the sociological possibilities of a linguistic liberation of the indigenous and Mapuche peoples.

Keywords: Mapudungun, linguistic ideologies, linguistic habitus, linguistic violence, linguistic decolonization

Chicham tsatsamáamu: Juka takatak emáamui batsatkamunum chicham imanchau disbauwa nui. Atsumnaawai dekas chichasbau amaina nunu, batsatkamun augtin nuigtu chicham aidaun jiitus augtin aina nunujai. Antsajik táaji wajuk takat emamainaita duka mai chichaman apáaju amain ainawai maak takat weti tabaunum. Wajuk takat ematasa anegtaimjamuita duka, Juu papíin augtin aidau chichakbauwa nunu aintsa emamaui Krotskity nuigtu Silverstein antsag takau aidau Pierre Bourdieujai. Jui wantinui waitkaniamu nuigtu wajuk chichainawa nunu Mapuchenmaya mapudungun chilenum. Juka papik augtusbauk anentainum júukmakam jugawai, jiyanittsa diyamu, wajuk tuinakjia iinbau chicham antsag Mapuchesh agkan chicháamush amainaita nunu.

Chicham Etéejamu: Mapudungun, Anegtaimsa emat chicham, Tuké Chichát, Ajáatusa Diyashbau chichát, Tajitbau Depetamkatatau, Agkagbaebau íina chichámechunum. 


\section{Introducción}

Las situaciones prolongadas de interacción lingüística afectan interna y externamente a las lenguas en situación de contacto/conflicto. En su ámbito interno, las lenguas, sobre todo las minorizadas, pueden experimentar proceso de modificación estructural en el nivel morfosintáctico y fonológico. Externamente, la interacción entre lenguas distintas produce fenómenos como el cambio de código, préstamos lingüísticos y la transformación de las valoraciones de estas y las significaciones asociadas a su uso (Bailey, 2007). En general, la lingüística, dada su preferencia por modelos inmanentistas y formalistas, funcionales a una perspectiva colonialista del contacto/conflicto lingüístico (Errington, 2008), no ha podido por si sola caracterizar toda la gama de fenómenos externos de modificación de las prácticas lingüísticas. En particular la caracterización de situaciones de dominación lingüística y de bilingüismo en situaciones coloniales requieren de un profundo diálogo interdisciplinario (Stroud, 2007).

Los antecedentes de este diálogo los encontramos en la idea de racionalizaciones secundarias sobre la lengua, evidenciada primero por Frank Boas (1911), aunque paradojalmente proscritas por él en la labor etnográfica, que son la puerta de entrada para atender a las conceptualizaciones que hacen las propias comunidades hablantes sobre sus propias lenguas, aspecto que Whorf (1941) reimpulsó posteriormente en sus reflexiones sobre "representaciones metalingüísticas". Uno de los desarrollos más interesantes, que explora fenómenos como la estigmatización y marginalización de lenguas, así como la construcción de lenguas hegemónicas, son las ideologías lingüísticas [Silverstein (1979), Irvine (2000), Kroskity (2010), Hauck (2014), Ojeda \& Álvarez (2014), Lagos (2016)]. Desde esta perspectiva se analizan fenómenos como las actitudes y lealtad frente a la lengua, así como la construcción social de esquemas de percepción y valoraciones sobre ellas. Estos estudios caracterizan la acción ideológica como productora de lenguas hegemónicas, minorizadas, ilegítimas, variedades de bajo prestigio, entre otras.

Sin embargo, a la luz de la evidencia sobre formas post ideológicas de dominación simbólica y lingüística, se hace urgente avanzar hacia una construcción social de las lenguas dominadas que incorpore, por ejemplo, los conceptos de habitus y violencia lingüística desarrolladas por Pierre Bourdieu (1981, 1991, 2002). Esta perspectiva aporta una mirada que entiende la situación de dominación lingüística como una forma de violencia simbólica expresiva de estructuras globales de dominación.

La situación del Mapudungun, lengua del pueblo nación mapuche que habita las regiones centro sur de Chile, ofrece evidencias importantes para la caracterización sociológica de la dominación lingüística. 


\section{Metodología}

Este trabajo es de carácter exploratorio y reflexivo. Se basó en la sistematización de fuentes primarias y secundarias. Respecto de las fuentes primarias, se realizó una revisión de alcance de la literatura o scoping review (Arksey \& O'Malley, 2018) sobre los siguientes criterios: a) ideologías lingüísticas b) violencia lingüística c) ideologías lingüísticas en Chile y el Mapudungun. La revisión de literatura se realizó consultando las siguientes bases de datos: Web of Science (WoS), SCOPUS, SCIELO y Google Scholar. Respecto de las fuentes primarias, estas provienen de la revisión de material etnográfico propio levantado en el contexto de dos estudios: Fondecyt Iniciación 11110362 "Caracterización etnolingüística de producción y reproducción de la lengua mapuche rural en comunidades pehuenches de Pitril y Caillaqui, Alto Bío-Bío"y el trabajo de tesis para el magister en Ciencias Sociales de la Universidad de Chile, realizado en una comunidad mapuche de la zona del Lago Lleu Lleu (Octava región de Chile) (Alvarez, 2015). Este artículo explora preguntas planteadas en un artículo anterior (Ojeda \& Álvarez, 2014) sobre la construcción social de la lengua mapuche.

\section{Ideologías lingüísticas y Mapudungun}

La teoría de las ideologías lingüísticas (IL) entronca con el trabajo de la sociolingüística y el estudio de las actitudes lingüísticas (AL). Hereda la preocupación respecto de las valoraciones que los hablantes tienen sobre sus prácticas lingüísticas y las que circulan en la sociedad. Una actitud lingüística es típicamente una referencia a la propia lengua y en segundo lugar a otras lenguas o variantes. Se construye de la experiencia de contacto por una lógica decontrastante -nuestra lengua o variante/otras lenguas o variantes- como sintaxis binomial que reescribe en cada dimensión de la lengua o variante la idea desfavorable/desfavorable. Por ejemplo, una actitud típica es asumir que una lengua es estéticamente superior a otra como resultado de sus características internas, gramáticas, fonéticas, etc. Así, una actitud lingüística de un grupo social y culturalmente posicionado acerca de una práctica lingüística, propia o externa se ubicará en la gradiente que va de los favorable o desfavorable (Edwars, 2009). El modelo epistemológico de las actitudes lingüísticas es la psicología social. El concepto de actitud busca explicar el paso de la mente a la acción. Para que suceda se tienen que dar tres condiciones: emociones (componente afectivo), creencias (componente cognitivo) y una predisposición afectiva (componente conductual). (Edwars, 2009). En el caso del Mapudungun se han estudiado las actitudes lingüísticas positivas de los docentes interculturales mapuche a cargo de la educación bilingüe respecto de su lengua (Olate y Henríquez; 2010).

La perspectiva de las ideologías lingüísticas busca analizar desde la historia y dotar de sentido político las variaciones favorabilidad/desfavorabilidad frente a 
una lengua en relación con la posición e intereses sociales de quienes las enuncian. Atiende fundamentalmente a los procesos de minorización, marginalización y estigmatización de lenguas, dialectos y variantes, y su relación con la legitimación de otras. Adicionalmente, las ideologías lingüísticas toman los desarrollos de la Antropología lingüística con el objeto de ampliar los contextos que afectan a las prácticas lingüísticas. De ambas tradiciones se hereda una base epistemológica enraizada en las teorías del conocimiento y el enfoque cognitivo.

El enfoque de "ideologías lingüísticas" ha adquirido un desarrollo importante en las últimas décadas (Irvine \& Gal 2000, Silverstein 1979, Hill 1985; Jaffe 2003; Makihara \& Schieffelin 2007; Kroskrity 2010, 2017), con una amplia utilización en los estudios sobre lenguas en contacto en Europa y Estados Unidos, pero solo recientemente aplicada la realidad chilena y sus lenguas en contacto/ conflicto (Makihara y Schieffelin 2007, para la lengua Rapa nui; Abarzúa 2016, para la lengua aymara; Lagos 2015, 2017; Lagos \& Espinoza 2013; Lagos et al 2013; Ojeda y Álvarez 2014; Pérez de Arce 2016; Cisternas 2017; Olate et al 2017; Quiroga 2018, para la lengua mapuche). La noción de "ideología lingüística" es el resultado de la evolución de los planteamientos originales de F. Boas (rescatando la existencia de elaboraciones secundarias en los hablantes sobre sus lenguas) y B. L. Whorf, y los posteriores aportes de D. Hymes y J. Gumperz. Puede ser entendida como el conjunto de "creencias, sentimientos y concepciones, planteadas de manera explícita o manifestadas en prácticas comunicativas, acerca de la estructura y uso del lenguaje, que a menudo responden a los intereses políticos de los hablantes individuales, grupos étnicos y de otros intereses y los Estado naciones" (Kroskrity 2010: 192), poniendo así de manifiesto la naturaleza social e históricamente situada de la cultura acerca del lenguaje. De esta manera, corresponden a racionalizaciones que todos los hablantes -especialistas "científicos" del lenguaje e integrantes de las comunidades lingüísticas en general- realizan sobre las lenguas, sus funciones, su estructura, sus hablantes, sus conflictos, etc. La incorporación de la variable cultural que implica su uso permite que el análisis lingüístico se conecte con las relaciones de poder económico y político que juegan un rol central en la construcción social de las ideologías lingüísticas que los actores sociales -nosotros- hacemos sobre todo lo que nos rodea (incluidas las lenguas), factores que cobran gran relevancia cuando nos situamos en el terreno de las lenguas en contacto/conflicto (Errington 2008).

Kroskity (2010) señala que el primer impulso de la teoría de las ideologías lingüísticas tiene esta matriz -que llama análisis ideológico neutral- focalizado en las creencias y prácticas lingüísticas en su anclaje al contexto sociocultural en que operan. En la actualidad, algunas de las definiciones de ideología lingüística utilizadas contienen directamente esta idea. De los Heros (2007) dice que las ideologías lingüísticas son las creencias sociales compartidas que se refieren al uso y al valor de las lenguas. Hirsh et al (2006) señala acerca de las ideologías lingüísticas: "el lenguaje y la significación son inseparables de la materialidad y la acción". 
En un segundo momento, según Kroskity, se incorpora elementos de la lingüística crítica y, con ella, la teoría marxista. Se analiza la función de las ideologías lingüísticas para la construcción de hegemonías lingüísticas en el marco de relaciones de clases en una sociedad. Ambas líneas -análisis ideológico neutral/análisis crítico de las ideologías- son validadas y están presentes en las operacionalizaciones que hoy se hacen del concepto de IL. En suma, se trata de un concepto multidimensional en el que se superponen cuatro capas de significación que lo dotan de poder explicativo y rendimiento analítico:

1. Las ideologías lingüísticas representan valoraciones acerca del lenguaje y los discursos construidos en función del interés de un grupo social específico. Aquello que es "verdadero", "moralmente bueno", o "estéticamente agradable" acerca del lenguaje se vincula directamente a la posición social de los grupos que las producen y difunden. En tanto los grupos sociales y culturales se oponen entre ellos según su posición de clase social, género, etnia, cultura, lengua; sus representaciones y actitudes respecto de las lenguas no pueden desinteresarse de esa o-posición. Las ideologías lingüísticas dominantes: estándar, monoglósica, monolingüe son producidas por élites políticas y económicas en diferentes partes del mundo. El poder de esos grupos aumenta la capacidad de difusión ideológica, haciéndolas hegemónicas. La sanción institucional favorable a una lengua estándar, por ejemplo, es el resultado de un trabajo de mitificación de las prácticas lingüísticas del grupo dominante conseguido mediante el control institucional, educacional y mediático. La función ideológica de esas instituciones es difundir y legitimar el reconocimiento y la valoración del lenguaje estándar junto a otros aspectos de la cultura dominante, al mismo tiempo devaluar las expresiones culturales lingüísticas divergentes. En esta dimensión la teoría de las ideologías lingüísticas se acerca al marxismo en su interrogación respecto de la relación entre capitalismo, estado e ideología.

2. Las ideologías lingüísticas son siempre múltiples, en tanto múltiples son las formas de estructuración social (clase, género, etnia, generación, religión, etc.) en las sociedades capitalistas. Al interior de un grupo sociocultural existe el potencial de producir ideologías lingüísticas divergentes. No hay introyección insalvable e inmediata de las ideologías lingüísticas dominantes en los dominados. Existe dentro de los hablantes una amplia variedad de ideologías lingüísticas como facciones y subgrupos entre ellos. Tampoco los dominados están condenados a la falsa conciencia, a la legitimación del orden que los domina mediante la operación ideológica urdida por el poder. Todos los grupos producen ideologías, que es conocimiento existencialmente arraigado por medio del cual traducen sus intereses en contextos de interacción social con otros grupos. 
3. Los miembros de un grupo sociocultural pueden presentar diferentes grados de asimilación de la ideología lingüística. Si bien la ideología lingüística tiene la pretensión de hacerse universal/natural en todo el cuerpo social, su efecto es más fuerte en el entorno social inmediato donde es producida. Esta capa significativa del concepto apunta a un modelo de transmisión de discursos ideológicos mediante su difusión en instituciones y medios. La efectividad del mensaje tiene que ver con la exposición en la radio, la escuela, la iglesia, el ejército, etc. Lógicamente, los primeros consumidores de esos discursos son los mismos grupos que la producen. Orgánicamente vinculados a esa ideología lingüística, la naturalizan en mayor grado. Su efectividad siempre será menor donde se encuentra en abierta contradicción con la realidad.

4. La ideología lingüística es producida y reproducida en contribución del cuerpo de científicos lingüísticas y su influencia sobre el sistema educativo. En el campo académico de la lingüística se introducen ideologías políticas que movilizan creencias y representaciones acerca de las otras clases, etnias y culturas que se traspasan a sus análisis acerca de las lenguas y variantes lingüísticas del territorio nacional. Este punto remite a la función de las lingüísticas en el proceso de estandarización "codificación y aceptación, dentro de una comunidad de hablantes, de un conjunto de normas que definen los usos correctos: ortografía, gramática y diccionario" (Moreno Fernández 1998). Luego, el sistema educativo contribuye a la perpetuación de esta ideología lingüística estándar. Así, en sus usos lingüísticos los distintos grupos sociales adhieren a la norma lingüística definida por el cuerpo de lingüísticas que reproducen ideologías políticas dominantes.

El cuerpo de lingüísticas reproduce ideologías políticas, por ejemplo, sobre la comunidad nacional mono-cultural. Desde ese prisma, la diversidad y la variación se perciben como una desviación (Milroy, 2001). En ese sentido, el campo de la lingüística reproduce ideologías políticas que se especifican por ejemplo en las tecnologías de estandarización lingüística. Como señala Siegel (2006) "El proceso que media entre la estandarización y la construcción de una lengua hegemónica es ideológico". Estos conceptos, comunidad cultural y monolingüismo son ataduras ideológicas que vienen de la consolidación de los Estados Nación entre el siglo XVIII y XIX. (de los Heros, 2007 y 2008).

Para entender la situación de dominación histórica del Mapudungun respecto del español se deben revisar dos construcciones ideológicas: monolingüismo y español estándar. Las representaciones y creencias ancladas en ambas remiten a las prácticas lingüísticas de las élites blancas, descendientes de españoles y europeos que construyeron el Estado chileno y monopolizan el poder económico y cultural. Élites cuyo influjo ideológico será contrarrestado recién con 
la propagación de ideologías contra-hegemónicas entrado el siglo XX (Salas, 2006). El monolingüismo se enarboló enmascarado en una epistemología racionalista propia de la doctrina liberal de las élites controladoras del estado. En esa lógica, el español sería un instrumento de comunicación para participar en plenitud de la vida social, cultural y política del país. Los grupos indígenas, especialmente los mapuches, debían abandonar su lengua si pensaban entrar en alguna clase de debate político. El sistema educativo debía impedir la formación de dialectos. El control político sobre el territorio nacional y la población impone la lógica del control lingüístico del territorio nacional.

El español-chileno como lengua estándar moviliza la creencia de que la lengua estándar es más dinámica y adecuada para la modernidad que los dialectos o variedades marginales. Esto tiene efectos muy precisos en las comunidades hablantes:

"Hablar el estándar es así como marcador de una educación apropiada, de un mayor nivel de empleo y de acceso a ocasiones formales. Las variedades marginales sólo son apropiadas para conversaciones casuales, bromas y ocasiones informales. Representa a la variedad estándar como una forma más sofisticada y superior de habla que por lo tanto debe ser promocionada para ciertos usos y contextos, sobre todo los formales y académicos". (Siegel, 2006, p.159)

En síntesis, la ideología del español estándar constituye una fetichización de las prácticas lingüísticas de las élites dominantes chilenas, y que ha variado (poco) conforme nuevos grupos han accedido al poder. Es esencialmente la reproducción de prejuicios respecto de las variedades populares del español, urbanas y campesinas, así como de las lenguas indígenas.

\section{Violencia lingüística y Mapudungun}

¿Cómo caracterizar las prácticas lingüísticas de un grupo social dominado? El fenómeno de la dominación, por el cual uno o varios grupos devienen subalternos, alcanza, en la situación colonial, todas o casi todas las dimensiones de la vida social: política, económica, cultural, lingüística, etc. Las ideas de los grupos dominantes, sus operaciones ideológicas, cumplen una función capital en la legitimación de la dominación. No obstante, la extensión subjetiva de ese proceso no se agota en el plano de las ideas y las ideologías. Las teorías que examinan los procesos de simbolización de la vida social han demostrado que esas construcciones solo son parcialmente conscientes; que tienen vida colectiva y que no emergen de sistemas de conocimiento elaborado. De hecho, se trataría de procesos inconscientes y colectivos a la vez.

Nuestros gestos, actitudes, hábitos, en los que rara vez se repara, no pueden ser explicados al margen del colectivo que las pone a circular. Tampoco 
nuestra percepción y apreciación del gusto, la belleza, el orden, etc. El conjunto de esas prácticas culturales (simbólicas), que van desde hábitos hasta elaboraciones complejas como la religión y el lenguaje, no contienen su realidad última en el pensamiento de algún individuo. Se producen y reproducen colectivamente y se anidan en el sentido práctico de las personas, que encarnan y corporizan. Y es justamente ese el ámbito donde se encuentra el último eslabón del proceso de dominación. Se debe, en consecuencia, diferenciar entre estos dos ámbitos de dominación: las ideas -vía ideologías-; las prácticas culturales -vía violencia simbólica-

Teóricamente las ideologías lingüísticas constituyen un momento dentro de ese complejo que es la relegación social de una lengua o una variante a la marginalidad. Momento que tiene que ver con la articulación de creencias y representaciones anidadas en la conciencia de los hablantes y su circulación en el espacio social. Más allá de las ideologías, en lo profundo de la subjetividad de los hablantes que se despliega en las interacciones lingüísticas, está el ámbito de la violencia simbólica: categorías con que percibimos, apreciamos y jerarquizamos nuestra propia lengua.

¿Qué papel juega el lenguaje -práctica cultural elemental- en los procesos de dominación? ¿De qué manera se ejerce dominación por intermedio de las prácticas lingüísticas?

Las preguntas planteadas señalan una dirección: existe un correlato de la violencia simbólica, la violencia lingüística. Bourdieu (2002) propone una estructura general en la que se desarrollan las prácticas lingüísticas cuya caracterización permite distinguir en qué orden se aplica la violencia lingüística. Propone el siguiente modelo: toda práctica lingüística es el resultado de la interacción entre un habitus lingüístico y un mercado lingüístico. La ecuación es la siguiente:

\section{Habitus lingüístico + mercado lingüístico = expresión lingüística.}

Para acercarse al fenómeno de la violencia lingüística se requiere analizar el lenguaje más allá de su función comunicativa. El contacto cultural y el bilingüismo no explican, por sí mismos, cómo una lengua deviene marginal. Por ejemplo, condenar al silencio, "callarse" porque no se sabe "hablar correctamente" es en sí una práctica lingüística. Está condición conecta con un esquema general de valoraciones sobre las lenguas en contacto. En ese esquema, las lenguas o variantes minoritarias son construidas como un marcador de estigma social. Este esquema permite conceptualizar las prácticas lingüísticas que se dan en situaciones de contacto asimétricas.

Tradicionalmente la lingüística ha integrado al análisis el condicionamiento social de los hablantes por medio de dos conceptos: situación y contexto. Señala 
Bourdieu (2001) que la "situación" introduce un contexto reducido que no alcanza a reflejar lo social en las prácticas lingüísticas. Aquello a que apunta la situación lingüística, una interacción social específica, por ejemplo una conversación, no da cuenta de la posición social de los hablantes, de toda la carga simbólica que esas prácticas lingüísticas pueden estar reflejando.

"Las relaciones lingüísticas de fuerza transcienden la situación, son irreductibles a las relaciones de interacción tal y como se pueden captar en la situación" (Bourdieu, 2002, p 151).

Para Bourdieu una interacción lingüística, desarrollada en un contexto, es también un intercambio económico (más adelante se explicará a qué se refiere) que se lleva a cabo en una cierta relación simbólica de fuerzas entre un productor, provisto un cierto capital lingüístico, y un consumidor al interior de un "mercado", apto para procurar un cierto beneficio material o simbólico.

"Dicho con otras palabras, los discursos no son únicamente (cuando son sólo excepcionalmente) signos destinados a ser comprendidos, descifrados; son también signos de riqueza destinado a ser valorados, apreciados y signos de autoridad destinado a ser creídos y obedecidos" (Bourdieu, 2001, p.40).

La práctica lingüística informa sobre la manera diferencial de comunicar, es decir, sobre el estilo reflexivo que percibimos apreciado en referencia al universo de los estilos de vida aparentemente competitivos, con gran valor social y eficacia simbólica.

Ese "estilo de comunicar" es expresión del habitus lingüístico que a su vez es una dimensión particular del habitus que expresa una simbolización de la posición social: sentido práctico, encarnado, opera como sistema de esquemas generadores de prácticas y de percepción de esas prácticas, "competencia inseparablemente técnica y social (a la vez capacidad de hablar y hacerlo de una determinada manera, socialmente marcada)" (Bourdieu, 1982). El habitus se estructura multidimensionalmente en los diferenciales de capital (económico, cultural, social, político y lingüístico) que definen las coordenadas de posición social en el espacio social(4). El habitus lingüístico pone en marcha esquemas de apreciación y percepción de la lengua que son objetivas a la posición de cada grupo social. Se adquiere en los intercambios familiares, en la vida al interior de un barrio y la escuela; son modelos y sanciones acerca de la lengua que aprenden los miembros jóvenes del grupo por mimesis práctica, pre-reflexiva, por una suerte de encarnación.

(4) Quienes ocupan una posición dominante en el espacio social se caracterizan por la acumulación de capital: político económico y cultural. tienden también a concentrar otros tipos de capital simbólico (tasa de convertibilidad del capital). 
En consecuencia, el habitus lingüístico expresa la concentración de capital simbólico (lingüístico) desigualmente ${ }^{(5)}$ distribuido en el espacio social. Soporte de lo que en lingüística se llama "competencia" (talento para escribir, leer, hablar, escuchar, entender el contexto plurilingüe y pluricultural). El capital lingüístico corresponde entonces a la posesión de competencias más o menos alejadas del uso legítimo de la lengua.

¿Cuál es la característica del habitus mapuche y más específicamente de su habitus lingüístico? A partir de nuestra experiencia etnográfica con mapuches bilingües y monolingües en español de las zonas del Lago Lleu Leu y de la zona de Ato Bío Bío, consideramos los siguientes elementos:

La característica de ese habitus lingüístico es su adecuación objetiva a la posición social que lo genera; posición económica, política y culturalmente dominada. En consecuencia, la primera particularidad del habitus lingüístico mapuche, el repertorio de competencias lingüísticas que despliega, es la distancia respecto del habitus lingüístico dominante poseedora del español estándar y de las competencias gramaticales, escriturales y discursivas que se reconocen como la norma lingüística. La posesión de esas competencias es la posesión de un capital simbólico-lingüístico.

Dado que los distintos habitus lingüísticos tienen un valor simbólico diferencial en relación con la posición social donde se generan, Bourdieu considera adecuada la idea de "mercado lingüístico(6)". Con ella el autor quiere reconstruir la lógica global de la interacción lingüística en una sociedad enfatizando las desigualdades de capital lingüístico en su interior. ¿Por qué hablar de mercado? Un mercado siempre es una relación de fuerzas. El campo económico, de prácticas propiamente económicas, es un espacio de lucha por la apropiación de bienes económicos y la acumulación de capital económico. Así, la idea de mercado nos permite entender la circulación y valoración de los productos lingüísticos como sistema de relaciones de fuerza lingüísticas fundada en la desigualdad

(5) Bourdieu advierte no hacer una lectura mecanicista del habitus: El habitus es histórico, genera disposiciones durables pero no perpetúas. La función del habitus es la adaptación, procesa la contingencia de cada nueva situación, en consecuencia experimenta transformaciones significativas. No obstante, mientras la posición social de cada grupo, en términos de concentración de capital, no se transforme, el habitus históricamente construido seguirá aportando los esquemas de percepción y apreciación idóneos a esa posición. Así sin transformación social las adaptaciones del habitus no pasan ciertos límites. "La situación es la condición que permite la realización objetiva del habitus. Aun así, los ajustes que impone la necesidad de adaptarse a situaciones nuevas e imprevistas pueden determinar transformaciones duraderas en el habitus, pero éstas no rebasarán un cierto límite, entre otras razones, porque el habitus define la percepción de la situación que lo determina" (Bourdieu, El mercado lingüistico, 2002).

(6) Habla de mercado lingüísticos y no utiliza la noción de campo por varios motivos: la idea de campo lingüístico puede generar confusiones respecto del campo académico del cuerpo de lingüistas. La idea de campo en Bourdieu siempre expresa una situación de mercado en tanto refiere a procesos de circulación, distribución, acumulación y concentración de bienes. Los campos son espacios de lucha por la acumulación de capital simbólico. 
de distribución capital lingüístico. En ese mercado lingüístico se valorizan las diferentes competencias lingüísticas ancladas a cada habitus lingüístico. "Todas las interacciones lingüísticas son tipos de micro mercados que están siempre dominados por las estructuras globales" (Bourdieu, 2002).

El capital lingüístico es el poder sobre la formación de precios lingüísticos respecto de los productos lingüísticos circulantes. En contraste, el habitus lingüístico producido en la comunidad mapuche no constituye ni se transforma en capital lingüístico redituable. ¿Por qué el habitus lingüístico mapuche no puede transformarse en capital lingüístico? El mapuche, su lengua y su variante del español poseen escaso valor real en el mercado lingüístico chileno. Tiene escasa legitimidad lingüística. Subsiste en mercados delimitados (espacio rural, ritual, académico). En verdaderos islotes socioculturales por fuera de las leyes del mercado.

Respecto de la situación colonial, propia de las comunidades mapuches, la idea de mercado simbólico y mercado lingüístico resulta especialmente adecuada. Bourdieu, siguiendo a Polanyi ${ }^{(7)}$, sostiene que un mercado (de prácticas económicas) capitalista es siempre una realidad construida por la acción de un Estado nacional moderno. La imposición de un mercado es un proceso de dominación política. El mercado capitalista se impuso en territorio mapuche mediante la acción colonial chilena. Se buscaba la incorporación de ese territorio y la mano de obra a los esquemas productivos nacionales ${ }^{(8)}$. Resulta de esa anexión colonial del territorio y su población la unificación del mercado económico y su apertura a los mecanismos de formación de precios en la economía. Se introducen los criterios dominantes del valor económico: fijación neutral de los precios y conductas instrumentales mercantiles asumidas como universales. Contrario a lo que sostienen muchos de los modelos utilizados por economistas, la unificación del mercado económico dista de ser un arreglo o ajuste entre individuos y mercado. En realidad, la intervención del Estado crea y asegura mercados para los capitalistas nacionales. Colocados en esa situación, los bienes económicos mapuches, por ejemplo, su producción agraria y ganadera es inmediatamente devaluada por la unificación del mercado económico. Además de la usurpación, expoliación y destrucción de sus medios de producción, la fuerza de trabajo mapuche incorporada al mercado del trabajo se posiciona estructuralmente devaluada, condenada a circular como mercancía barata (Bengoa, 1985). Toda la producción agrícola y ganadera mapuche reducida a economía de subsistencia.

La idea de unificación del mercado lingüístico es útil para examinar la situación de las lenguas indígenas en contextos poscoloniales latinoamericanos.

(7) Ver "la gran transformación" de Karl Polanyi (2018).

(8) Cronológicamente primero se impuso un tipo de capitalismo agrario, con elementos de economía hacendal. Desde los últimos decenios del siglo XX se produce progresiva capitalización y modernización vía inversión nacional y extranjera en la figura de la industria forestal. 
Los productos culturales de los grupos sometidos, como el mapuche, corren la misma suerte. El sometimiento político y económico implica al mismo tiempo la unificación del mercado de bienes simbólicos. Así, la producción y circulación de bienes culturales mapuche (religión, arte, valores, creencias, lengua), antes dirigida a su propio mercado, son forzados a una apertura al mercado cultural chileno y llevados a su rápida devaluación. Ese mercado impone y generaliza sistemas de valoración cultural ajenos a la cultura mapuche, por la acción de campos como el educacional, político y los medios de comunicación. En otras palabras, a los grupos indígenas se les arrebata la capacidad de valorar sus bienes simbólicos. En contrapartida, ese mecanismo valoriza los productos culturales de los grupos dominantes que a su vez se encuentran concentrados por ellos. Es en la práctica, la condena progresiva a la obsolescencia del habitus mapuche, sus prácticas económicas y culturales junto con sus productos económicos y culturales (lógicas de trabajo y acumulación, estrategias de intercambio matrimonial, organización religiosa, arte, etc.).

El sometimiento político, económico y cultural del territorio mapuche implica, en esta lógica, la unificación del mercado lingüístico, y la imposición de unas relaciones de fuerza lingüística en su interior. La anexión del territorio mapuche significó la anexión lingüística de la población. Cada interacción lingüística expresa, desde este punto de vista, una relación de fuerzas lingüísticas. El resultado es el desplazamiento funcional del Mapudungun en tanto no participa de los mercados linguisticos regulados por el Estado; la escuela, las institituciones estatales, medios de comunicación, por nombrar algunos. En eso descansan las condiciones de dominación lingüística del español sobre el Mapudungun. La legitimación de esa situación vía ideologías que naturalizan (ámbito de las ideologías linguisticas), la relación español-nación chilena.

La acción ideológica de la escuela es fundamental en tanto impone el reconocimiento universal del español. Ahí se cautela el aprendizaje y uso de la lengua correcta mediante el somentimiento universal al examen y sanción lingüística. Más importante, el sistema escolar chileno logró legitimar la distribución desigual del conocimiento del español estándar y al mismo tiempo legitimar la distribución mucho más homogénea del reconocimiento de la legitimidad de esa lengua. Eso sucede porque la escuela naturaliza una variante del español, su pronunciación, léxico, construcciones gramaticales, como la norma lingüística estándar. En efecto, su acumulación constituye capital lingüístico. ¿Cómo afecta la posesión de ese capital lingüístico en la interacción lingüística, especialmente donde hay diferenciales significativos de capital lingüístico? El hablante poseedor de capital lingüístico (dominio de la norma), es normalmente representante de los grupos dominantes, moviliza el reconocimiento de su modo de comunicar y con ello refuerza el mensaje de su comunicación. Es decir, que la violencia lingüística tiene eficacia simbólica. 
Siguiendo a Bourdieu (2002), la violencia simbólica es aquella que se ejerce sobre una persona predispuesta (en su habitus) a sufrirla. Implica una forma de complicidad que no es coerción física ni sumisión pasiva. La violencia lingüística en particular es aquella que se origina en el proceso de simbolización de las relaciones de fuerza lingüística donde se inserta la comunicación. Se produce en tanto el habitus lingüístico dominado, devaluado, se predispone a aceptar y legitimar esa posición en cada interacción lingüística en particular en aquellas donde concurren portadores de la norma o capital lingüístico. Así, aunque se valore sinceramente el Mapudungun y opere efectivamente en micro mercados lingüísticos de la comunidad mapuche, la práctica lingüística más frecuente del hablante del Mapudungun o del bilingüe es la autocensura de sus expresiones ${ }^{(9)}$. El habitus lingüístico mapuche produce esquemas de cálculo espontáneo, categorías de percepción y apreciación de la lengua que origina prácticas lingüísticas que son anticipaciones respecto de las interacciones lingüísticas donde debe concurrir. El mapuche no puede pensar su propia lengua sin aplicar los instrumentos que el español pone en circulación para legitimarse.

"Tratándose una producción simbólica, la conexión que el mercado ejerce mediante la anticipación de las posibilidades de beneficio remiten naturalmente la forma de una censura anticipada, de la autocensura, que no sólo determina la manera de hablar, la elección del lenguaje, como es el caso del cambio de código en situaciones bilingües. En cada interacción se revela quién es el poseedor de la norma lingüística. Las situaciones de bilingüismo permiten observar en forma casi experimental las variaciones de la lengua empleada en función de la relación entre los interlocutores y de su instrumento de expresión, en la estructura de la distribución del capital propiamente lingüístico y otros tipos de capital". (Bourdieu, 2001, p.51)

A partir de esta perspectiva se puede plantear: ¿Qué expresa la pérdida de vitalidad del Mapudungun en las comunidades mapuche? ¿Qué expresa su desplazamiento funcional, su restricción a un puñado de micro-mercado (familiar, coloquial, ritual productivo)? Desde la perspectiva de la violencia lingüística, expresan la desintegración cultural y social a la que ha sido arrojada la sociedad mapuche a partir de la mal llama la pacificación de la Araucanía. En menos de cien años se pasó de una situación mayoritariamente monolingüe vernácula a la virtual extinción de esa lengua. El resultado, un bilingüismo históricamente desincentivado por la escuela, instituciones y medios de comunicación que tiene por efecto la interrupción de la enculturación del Mapudungun.

La baja vitalidad del Mapudungun (Lagos 2005; Gundermann et al, 2008), expresa esa situación en la medida que han sido los propios colectivos mapuche,

(9) El silencio es una práctica lingüística que difícilmente puede ser captada por los instrumentos que aplica la sociolingüística (encuesta y análisis de datos) y que sin embargo tiene una relevancia fundamental para esa comunidad de hablantes. 
agentes determinantes de su desplazamiento funcional en favor del español. Las sucesivas generaciones fueron desincentivadas del aprendizaje y uso del Mapudungun, en favor del aprendizaje del español. El habitus lingüístico mapuche se funda en la estigmatización del Mapudungun resultando un bilingüismo en retroceso (Zúñiga, 2007); y un español mapuchizado muy alejado del estándar y desvalorizado. Así, sin poder hacer otra cosa que subvalorar su lengua vernácula y sus competencias en español. El habitus lingüístico mapuche comporta anticipaciones y sanciones sobre dónde, cómo, cuándo y con quién hablar. Es esquema de percepción y apropiación de la propia competencia lingüística lleva a la autocensura y la desvalorización de formas expresivas. El cálculo inconsciente de un óptimo entre formas expresivas y comunicativas desvalorizadas lleva a que con el tiempo, la propia función comunicativa se vea afectada. El silencio.

\section{Ideologías lingüísticas contra-hegemónicas}

El siguiente apartado tiene por objeto introducir una propuesta teórica. Reflexionar sobre un objeto que ha sido escasamente estudiado por la teoría de las ideologías lingüísticas y en general por el análisis de los procesos de dominación a través del lenguaje. Nos referimos a la puesta en marcha de operaciones ideológicolingüísticas, por parte un grupo cuya lengua se encuentra dominada. Procesos de descolonización política y cultural que se especifican en la defensa de las lenguas vernáculas y las prácticas lingüísticas. Es cierto que la teoría de las ideologías lingüísticas, por su matriz en las teorías del conocimiento, no cae en el automatismo de la teoría marxista de la ideología -ideología de los de arriba para dominar a los de abajo- Sin embargo, no se ha explorado, salvo contadas excepciones, las ideas, creencias y representaciones generadas por los grupos subalternos para defender y promover su lengua. La sociolingüística laboviana usó la noción de prestigio encubierto (covert prestige) para explicar por qué algunas formas no estándar persisten en el tiempo a pesar de los esfuerzos por estigmatizarlas y erradicarlas (Schiffman, 1997). Ese prestigio encubierto sería robusto al punto que para ciertos grupos el cambio a una variedad estándar es una traición a la identidad grupal. Edward (2009) habla de una función de solidaridad del lenguaje. Kroskity (2010) se limita a señalar que el fenómeno del activismo lingüístico -language renewal- corresponde a una confrontación que se da en el orden ideológico en tanto ese es el marco que envuelve toda interacción entre el Estado y por ejemplo los grupos indígenas.

Como se ha señalado en este trabajo, todos los grupos sociales fundamentan sus actitudes respecto de los otros grupos sociales. Esa construcción, anidada en la conciencia de los sujetos, es una construcción ideológica. La fuerza de las ideologías depende del control sobre los medios de producción ideológica; medios de comunicación, escuela, religión, entre otros. Una ideología contra-hegemónica se define entonces como aquella que debe contrarrestar la función propagandística que los dominantes utilizan para difundir sus ideologías. Debe, por lo tanto, asegurar que 
las creencias, representaciones y opiniones que circulan en ese grupo correspondan objetivamente a su posición social e interés colectivo. Para ello, hay que exponer que la ideología dominante sirve al interés de los grupos dominantes.

La noción de contra-hegemonía proviene de la reflexión neo gramsciana de autores como Laclau, Tony Neri y Michael Hart (Eagleton, 1997). La contrahegemonía es el movimiento que busca desanclar las construcciones ideológicas que legitiman una situación hegemónica. Busca dar cuenta de las condiciones de posibilidad para la construcción de una conciencia política autónoma de los sectores y saberes subalternos. Desnaturalizar los conceptos, creencias y representaciones que ha erigido la ideología dominante para así multiplicar los escenarios de disputa. Es un movimiento de articulación orgánica entre las prácticas culturales y los intereses específicos al interior de las capas subalternas, dispersas y contradictorias, en un cuerpo ideológico consistente con capacidad real de disputarle la conciencia de los sujetos a la ideología dominante.

Respecto de la situación mapuche, el análisis debe apuntar a la idea de construcción de ideologías étnicas. Se ha propuesto que en aquellos sistemas interétnicos estructurados a partir de una situación colonial -contextos de ficción étnica- la gramática general de identidades (mecanismo de construcción de identidad por contraste a una otredad) yuxtapone los marcadores culturales de la diferencia étnica junto con marcadores de la posición social en la que los grupos han quedado como consecuencia de su incorporación a la estructura social capitalista del grupo colonialista. Es decir, la superposición de las identidades de etnia y de clase ${ }^{(10)}$.

Así, la sintaxis binomial de identidades nosotros/ustedes superpone marcadores culturales -nosotros esta lengua/ustedes esa- jerarquizados en función de la estructura de relaciones de fuerza étnica -nosotros indios/ustedes occidentales- de posición de clase nosotros campesinos-trabajadores/ustedes empresarios- políticos. Dice Cardoso de Oliveira(2007) que las representaciones a partir de las cuales se construye la identidad étnica integran valoraciones sobre la diferencia étnica; de hecho opera un etnocentrismo natural en tanto definimos al otro a partir de nuestras características puestas en una situación de interacción. En contextos de ficción étnica, donde la identidad deviene ideología, esas pautas de valoración se traducen en representaciones interesadas fundamentadas en la defensa de la posición de clase en la estructura social. Para el autor, los grupos oprimidos, como los indígenas amerindios, siempre arriesgan la posibilidad de desarrollar una ideología étnica alienada en tanto su control sobre la cultura de

(10) Hay que recordar que las identidades son múltiples y siempre refieren a una situación de contacto que impone la necesidad de identificarse, identificar al otro y ser identificado por el otro. Ver capítulo Posestructuralismo en "sistematización concepto de ideología en ciencias sociales". Barth concepto de identidad étnica. (Alvarez, 2014) 
contacto es reducida, por lo cual tienden a incorporar las representaciones de la sintaxis binomial producidas por la otredad dominante: el grupo colonizador.

Pues bien, el caso inverso, la construcción de una ideología étnica contra-hegemónica supone una relajación en el control sobre la cultura de contacto por parte del grupo dominante. Esto pasa por la diferenciación funcional que experimentan dichas instituciones como consecuencia del desarrollo del capitalismo. Es decir que las instituciones educativas y académicas, los medios de comunicación, así como los movimientos políticos urbanos cuestionan el modo de relacionamiento con el indígena y ponen a circular nuevos conceptos y representaciones de esa relación.

Al respecto es importante revisar los efectos que ha tenido la instauración del programa de educación intercultural bilingüe en algunas escuelas de Chile, así como la extensión del enfoque intercultural en la relación Estado-comunidades indígenas (Richards, 2019). En el ámbito específico de las ideologías lingüísticas da cuenta de tensiones que De los Heros denominó pluralismo igualitario e igualdad de oportunidades.

"La ideología del pluralismo igualitario, y la ideología de la igualdad de la oportunidad. Las dos ideologías son muy similares, pero enfatizan elementos diversos. Mientras que la del pluralismo igualitario enfatiza la igualdad de las lenguas, y el estándar como un recurso de escala social, la de la igualdad de oportunidades destaca el rol de la escuela y la adquisición del estándar para poder hacer que la sociedad sea más justa dando a sus miembros igualdad de oportunidades para triunfar en la vida" (De los Heros, 2008, p.100).

Esta tensión dentro de las ideologías dominantes entronca con los propios procesos de construcción de ideologías étnicas en las comunidades mapuche. Un desarrollo relevante en esa línea es el "control territorial" desarrollada en algunas comunidades mapuche vinculadas a la acción política de la Coordinadora Arauco Malleco (Pairicán, XXX; Álvarez, XXX) caracterizada por la defensa del territorio y las acciones de ocupación de territorio en manos de forestales y terratenientes. Se trata de una construcción etnoideológica que se nutre de ese excedente de significado que caracteriza a la mayoría de las culturas indígenas. Las creencias religiosas, ritos, lengua, arte, historia, prácticas económicas, entre otros. Ese material simbólico flotante es rescatado y subjetivamente escogido como significante de la identidad étnica. Para la ideología mapuche el pasado guerrero (weichafe) constituye un elemento central. Cómo veremos más adelante el rescate del significado del Mapudungun como "lengua de la tierra" es utilizado en un sentido similar.

Una ideología lingüística contra-hegemónica aparece en el contexto de la movilización política de un grupo social que porta una lengua dominada. Es decir, 
como uno, de entre varios repertorios de disputa con los grupos dirigentes. Sin que se cumpla esa condición parece poco probable que ésta pueda manifestarse. Así, una operación ideológico-lingüística es una especificación en el plano de la lengua de una construcción ideológica contra-hegemónica general. En esa disputa se enfrenta a las ideologías lingüísticas dominantes que a su vez son parte de construcciones ideológicas mayores.

¿En qué consiste una operación ideológico-lingüística contra-hegemónica? Refiere a la articulación de un conjunto de creencias, representaciones y conocimientos acerca de la propia lengua para contrarrestar la ideología lingüística dominante que legítima la lengua estándar y el abandono de la lengua o variante dominada. Opera como un repertorio de consignas para la defensa de la lengua. Dijimos más arriba que las comunidades mapuches han experimentado procesos de construcción de una ideología étnica contra hegemónica. Y que el material de esa construcción es el conocimiento tradicional resignificado a partir de conocimientos importados desde los centros urbanos. La defensa del Mapudungun mediante una operación ideológica se nutre primeramente del modelo romántico de lenguas que circula en la mayoría de las sociedades occidentales. Es decir, un reclamo a favor de la lengua en tanto comporta un medio de expresión fundamental para la identidad de un grupo. La imposición de la lengua estándar es entendida como vía de exclusión social de esa identidad.

Sabemos que esta idea romántica de la lengua tiene un origen académico, vinculado al trabajo del cuerpo académico de lingüistas y gramáticos. Es una idea esencialista y folkloristante que se ajusta muy bien a la demanda por la defensa de la lengua. El romanticismo lingüístico permite la re-significación de las creencias y representaciones vernáculas acerca de la lengua mapuche que es muy rica y diversa. Al respecto, los rasgos etnocéntricos y cosmológicamente fundados (Course, 2012) de la concepción tradicional del Mapudungun como "lengua de la tierra" o "lengua del territorio" movilizan significados útiles para la elaboración de la lengua mapuche como una etnolengua. La puesta en escena del Mapudungun como marcador central de su identidad es también una operación ideológica de descolonización lingüística, así como una expresión de las epistemologías multicultural, intercultural y plurilingüística que se han ido instalando en Chile.

Ahora bien, ¿Cuál es la capacidad de una ideología lingüística de resistencia para contrarrestar las ideologías lingüísticas dominantes? La historia reciente conoce procesos exitosos de revitalización lingüística como el País Vasco y Cataluña. No obstante desvincular dichos procesos al éxito de la política nacionalista que han impulsado sus comunidades sería una ingenuidad. En esos casos el desplazamiento funcional de su lengua se ha revertido reposicionándola en el espacio público y educativo. Respecto de los pueblos indígenas en América Latina, y del mapuche en particular, los avances son mucho menores. Si bien parece 
haberse constituido una tendencia ideológico-lingüística de resistencia al interior de muchas comunidades, donde los lingüistas mapuches han jugado un rol central, no parece revertirse significativamente la pérdida de vitalidad del Mapudungun. La causa de aquello probablemente esté en la persistencia de la estructura de dominio político y económico sobre las comunidades mapuche. En esas circunstancias, el habitus lingüístico mapuche sigue desenvolviéndose en un mercado lingüístico que concede escaso valor al Mapudungun. La estructura de relaciones de fuerza lingüística sigue actuando de modo que las prácticas lingüísticas desarrolladas al interior de las comunidades se adapten a la utilización generalizada del español. La violencia lingüística contra el mapudungun se sigue ejerciendo toda vez que introduce en el habitus lingüístico del mapuche la predisposición a dejar de hablarlo, relegarlo a contextos específicos, micro mercado lingüístico.

Más aún, la puesta en marcha de una ideología lingüística para la resistencia del Mapudungun parece replicar los mecanismos de violencia lingüística que aseguran su dominación. Para muchos intelectuales y lingüistas del mundo mapuche la preocupación fundamental es atraer capital lingüístico a su lengua. Reproducir toda la lógica del mercado lingüístico del que quiere escapar. Y para lograrlo se busca desmantelarla de los contextos donde aún subsiste. Existe una disputa que lleva décadas sin resolución entorno a la elaboración de grafemarios, estandarización del Mapudungun y terminar con su condición ágrafa. Aquello demuestra la incapacidad de pensar la propia lengua sin referir a la situación del español como modelo. Esa disputa reproduce la idea de que el Mapudungun es aún una lengua atrasada, incompleta; un instrumento de comunicación imperfecto. Un análisis relevante al respecto es el rol de las ideologías lingüísticas mapuche desarrollado en las comunidades Pewenche, sobre el efecto de segregador que tendrían para los jóvenes mapuche que no son hablantes de la lengua (Dinamarca \& Henríquez, 2019).

Finalmente hay que decir que las ideologías lingüísticas de resistencia comportan otro riesgo. La ideología lingüística de resistencia concede estatus y valoración a quienes son hablantes; por lo tanto se legitima su adscripción a posiciones dirigenciales. Por ejemplo, entre los Tapaties la revalorización de la lengua ha conducido a un enfrentamiento entre los miembros adultos y jóvenes de la etnia (Hirsch, González, \& Ciccone, 2006). La defensa e incentivo de la lengua ha conducido a que se establezcan estatutos donde quienes no la hablan quedan excluidos de la participación y de la toma de decisiones políticas. Así, una operación ideológico-lingüística puede deslizarse por toda la estructura social y política de una comunidad indígena y replantear los vínculos de relación en su interior: etario, género, status, religioso, etc.

\section{Discusión: revelar el arbitrario}

La lingüística no debe ignorar que la dominación lingüística, la construcción de lenguas dominadas/estigmatizadas/minoritarias es parte de un 
contexto general de dominación. No puede, por ejemplo, analizar el bilingüismo impuesto por una situación colonial sin introducir una perspectiva de cómo ese proceso, político, económico y cultural afecta la subjetividad y las prácticas culturales del grupo colonizado.

La dominación lingüística es una realidad terrible. Ocurre cuando los dominantes imponen al dominado la disolución de sus expresiones lingüísticas. La difuminación de su palabra, de sus formas de comunicar y nombrar al mundo. Cuando se lo condena al silencio. Es decir, cuando el control social es tan profundo que busca formatear la identidad del dominado.

La escuela funcionó para el mapuche como un aparato ideológico del Estado hasta finales del siglo XX. Los espacios de movilidad social y su incorporación a la carrera docente han modificado en algo esa situación. Recientemente, con los programas de educación intercultural bilingüe, la política de transformar al mapuche en chileno parece haberse relajado. Sin embargo, gran parte de la vida mapuche contemporánea se explica por la prolongación de las relaciones coloniales para con este pueblo. Aquello justifica y hace necesario el estudio de las ideologías lingüísticas incluida la que hay detrás de la educación intercultural bilingüe. Esta última, definida desde el Estado, contiene una ideología de la gestión participativa de la realidad multicultural y plurilingüística chilena. No constituye por sí misma, una forma de ideología lingüística contra-hegemónica. Por el contrario, producida desde arriba, en el ministerio de educación, debe ser leída como una ideología lingüística dominante.

De ahí la importancia de rastrear las codificaciones/operaciones ideológicas desplegadas para contrarrestar las ideologías lingüísticas dominantes. Observar la reintroducción en el ámbito de la lengua, de la ideología étnica mapuche que se construye, con distintos matices, por todo su territorio. ¿Qué tan efectivo resulta ese despliegue ideológico para contrarrestar la violencia lingüística del español sobre el Mapudungun? Probablemente muy poco. La ideología lingüística de resistencia probablemente genera grietas en el imaginario que el mapuche tiene sobre su propia lengua. Pero la violencia lingüística que ejerce el español hegemónico sobre todas las interacciones lingüísticas responde a la situación estructural en que se encuentran sus hablantes. Los procesos de simbolización de la vida social, naturales a la vida humana, no pueden dejar de referir a esa matriz. El punto es que la ideología no asegura que el habitus lingüístico mapuche deje de conducirlo al silencio.

Solo la movilización política por la defensa de la lengua, escoltada por una movilización general para conseguir la autonomía política y recuperar la tierra. Es decir, en la transformación de las relaciones sociales, políticas y económicas entre chilenos y mapuches cambian las relaciones de fuerza simbólica y el poder simbólico que los primeros ejercen sobre los segundos. Ese proceso, significado 
en construcciones ideológicas que le den fuerza y capacidad de difusión puede hacer frente a cien años de colonización. Y aun logrado eso, muy probablemente se mantengan y deslicen modos de sometimiento social y cultural.

Hoy se requiere alianzas amplias y generosas no solo con las clases populares, sino con sectores medios y empresariales (aquellos que se benefician del etnoturismo por ejemplo). Muy especialmente con el cuerpo de académicos críticos, sociólogos antropólogos y lingüistas. Estos últimos son los llamados a incorporar los efectos de dominación en sus análisis y desde ahí, proponer estrategias de resistencia lingüística que sean históricamente viables.

\section{Bibliografía}

ABARZÚA, L. (2016). Modelos culturales e ideologías lingüísticas tras las actividades de revitalización de la lengua aymara en Chile. Tesis para optar a Magister en Lingüística Española, Universidad de Chile.

BENGOA, José. 1985. Historia del pueblo mapuche (Siglo XIX y XX). Santiago: Sur. BOURDIEU, P. (2001). ¿Qué significa hablar? Madrid: Ediciones Akal.

BOURDIEU, P. (2002). El mercado lingüistico. En P. Bourdieu, Sociología y cultura (págs. 143-158). México D.F.: Grijalbo.

BOURDIEU, P. (8 de octubre de 1982). Ce que veut dire parler. (D. Eribon, Entrevistador)

CISTERNAS,C.2017.Ideologías lingüísticas:hacia unaaproximación interdisciplinaria a un concepto complejo. En, Lenguas y literaturas indoamericanas 19 (1): 101-117

COURSE, M. (2012). The birth of the word. Language, force, and Mapuche ritual authority. HAU: Journal of Ethnographic Theory, 1-26.

DE LOS HEROS, S. (2008). Ideologías lingüísticas sobre el estándar y las variantes regionales del español en dos textos escolares secundarios. Revista de Lenguas para Fines Específicos , 93-126.

DINAMARCA J, \& HENRÍQUEZ, M (2019). Una aproximación a las ideologías lingüísticas de hablantes Pewenches de la región del Bío Bío. Alpha (Osorno), (49), 334-351.

EAGLETON, T. (1997). Ideología una introducción. Barcelona: Paidos.

EDWARS, J. (2009). Language Attitudes. En J. L. Mey, Concise Encyclopedia Of Pragmatics Second Edition (págs. 416-421). Oxford: Elsevier.

EDWARS, J. (2009). Language Attitudes. En J. L. Mey, Concise Encyclopedia Of Pragmatics Second Edition (págs. 416-421). Oxford: Elsevier. 
ERRINGTON, J. (2008). Linguistics in a colonial world : a story of language, meaning, and power. Oxford, UK: Blackwell.

FOLIS, W. (1997). Anthropologicial Linguistics: An Introduction. Bejing: Blackwell Publishers Itd.

GUNDERMANN, Hans, Jacqueline Canihuan, Alejandro Clavería y César Faúndez. 2008. Perfil sociolingüístico de comunidades mapuches de la VIII, IX y X Región. Santiago: Universidad Tecnológica Metropolitana.

HAUCK, J. (2014). La construcción del lenguaje en Paraguay: fonologías, ortografías e ideologías en un país multilingüe. En, Boletín de Filología 49 (2):113-137.

HILL, J. (1985). "The Grammar of Consciousness and the Consciousness of Grammar". En, American Ethnologist, 12:725-37.

HIRSCH, S., González, H., \& CICCONE, F. (2006). Lengua e identidad: ideologías lingüísticas, pérdida y revitalización de la lengua entre los tapietes. INDIANA , 103122.

IRVINE, J. \& Gal, S. (2000). "Language ideology and linguistic differentiation". En P. Kroskrity (Ed.), Regimes of language, 35-84, Santa Fe, NM: School of American Research Press

IRVINE, J. \& Gal, S. (2000). Language ideology and linguistic differentiation. En P. Kroskrity(Ed.), Regimes of language, (págs. 35-84). Santa Fe, NM: School of American Research Press

JAFFE, A. (2003). "Misrecognition Unmasked? "Polynomic" Language, expert statuses and orthographic practices in Corsican Schools". En, Pragmatics 13:515-37.

KLINEBERG, O. (1986). Psicología Social. México D.F: Fondo de Cultura Económica.

KROSKRITY, P. (2017). Indigenous Tewa language regimes across time: Persistence and transformation. En, International Journal of the Sociology of Language (246): $7-30$

KROSKRITY, P. V. (2010). Language ideologies - Evolving perspectives. En J. Verschueren, \& J.-O. (. Östman, Society and Language Use (págs. 192-2011). Philadelphia: John Benjamins North America.

LAGOS, C. (2 015).“El Programa de Educación Intercultural Bilingüe y sus resultados: ¿perpetuando la discriminación?". Pensamiento Educativo Latinoamericano (PEL) $52(1): 84-94$.

LAGOS, C. (2017). Antropología lingüística y contacto lingüístico: ideologías lingüísticas en conflicto en contextos escolares de Pitril y callaqui, Alto Bío Bío. Revista Lenguas y Literaturas Indoamericanas 19: 117-131

LAGOS, C. \& M. ESPINOZA (2013). “La planificación lingüística de la lengua mapuche en Chile a través de la historia". En, Lenguas Modernas, 42: 47 - 66. 
LAGOS, Cristián, Marco Espinoza y Darío Rojas. 2013. Mapudungun according to its speakers: Mapuche intellectuals and the influence of standard language ideology. Current Issues in Language Planning (CILP) Vol 14, N 3: 1-16.

MAKIHARA, M. \& B. Schieffelin. (eds.) (2007). Consequences of Contact: Language Ideologies and Sociocultural Transformations in Pacific Societies. Oxford: Oxford University Press.

OLATE, A., C. Cisternas, F. Wittig \& J. Flores. (2017). "Los misioneros capuchinos bávaros y sus ideologías lingüísticas sobre la lengua mapuche". En, Nueva Revista del Pacífico 67: 130 - 156

PÉREZ DE ARCE, F. (2016). “Ideologías lingüísticas y representaciones sociales en torno a la enseñanza del inglés y del mapudungun. Tesis Magister en Lingüística Española, Universidad de Chile.

POLANYI, K. (2018). La Gran Transformación. Los Orígenes Políticos y Económicos de Nuestro Tiempo. Fondo de Cultura Económica.

QUIROGA, J. (2018). "Socialización lingüística del Mapudungún en hablantes y nuevos hablantes". Tesis para optar al grado de Magister en Lingüística, Universidad de Chile: Santiago de Chile

RICHARDS, P (2010). Of Indians and Terrorists: How the State and Local Elites Construct the Mapuche in Neoliberal Multicultural Chile. Journal of Latin American Studies, 42, pp 59-90 doi:10.1017/S0022216X10000052

SALAS, A. (2006). El mapuche o araucano. Santiago: Santiago: Centro de Estudios Públicos.

SCHIFFMAN, H. (13 de Noviembre de 1997). Handout for LING 540, Language Policy: University of pennsylvania. Obtenido de sitio web de University of pennsylvania: http://ccat.sas.upenn.edu/ haroldfs/540/attitudes/attitude.html

SIEGEL, J. (2006). Language ideologies and the education of speakers of marginalized language varieties: Adopting a critical awareness approach. Linguistics and Education, 157-174.

ZÚÑIGA, Fernando. 2007. Mapudunguwelaymi am? ¿Acaso ya no hablas Mapudungun? Acerca del estado actual de la lengua mapuche. Estudios Públicos 105: 9-24. 